\title{
ECG Planned Primary Lead for Study
}

National Cancer Institute

\section{Source}

National Cancer Institute. ECG Planned Primary Lead for Study. NCI Thesaurus. Code C119562.

A description of the ECG lead that is planned to be used as the planned, primary lead for the study. 